\title{
Médiévales
}

Langues, Textes, Histoire

70 | printemps 2016

Lieux d'hygiène et lieux d'aisance en terre d'Islam (VII $\mathrm{e}_{-}$ $\mathrm{XV}^{\mathrm{e}}$ siècle)

\section{Didier BARRIÈRE, Francisque Michel médiéviste et bibliomane romantique}

Bassac, Plein-Chant, 2014, 167 p. («Petite librairie du XIX ${ }^{\mathrm{e}}$ siècle »)

\section{Nicolas Weill-Parot}

\section{CpenEdition}

\section{Journals}

Édition électronique

URL : http://journals.openedition.org/medievales/7758

DOI : 10.4000/medievales.7758

ISSN : $1777-5892$

Éditeur

Presses universitaires de Vincennes

Édition imprimée

Date de publication : 23 juin 2016

Pagination : $277-278$

ISSN : 0751-2708

Référence électronique

Nicolas Weill-Parot, « Didier BARRIÈre, Francisque Michel médiéviste et bibliomane romantique »,

Médiévales [En ligne], 70 | printemps 2016, mis en ligne le 20 juillet 2016, consulté le 25 septembre

2020. URL : http://journals.openedition.org/medievales/7758 ; DOI : https://doi.org/10.4000/

medievales. 7758

Ce document a été généré automatiquement le 25 septembre 2020.

Tous droits réservés 


\title{
Didier BARRIÈRE, Francisque Michel médiéviste et bibliomane romantique
}

\author{
Bassac, Plein-Chant, 2014, 167 p. («Petite librairie du XIX ${ }^{\mathrm{e}}$ siècle »)
}

\author{
Nicolas Weill-Parot
}

\section{RÉFÉRENCE}

Didier BARRIÈRE, Francisque Michel médiéviste et bibliomane romantique, Bassac, Plein-Chant, 2014, 167 p. («Petite librairie du XIX ${ }^{\mathrm{e}}$ siècle »)

Pourquoi retracer la vie et le parcours intellectuel de Francisque Michel (1809-1887) ? Dans un volume aux allures «très $\mathrm{XIX}^{\mathrm{e}}$ " de la collection «Petite Librairie du XIX siècle ", Didier Barrière répond à cette question, tout en gardant la sévère distance critique qui s'impose face à un personnage que ses contemporains ont qualifié tour à tour de «crapaud» (Eugène Burnouf), de «cuistre » (Charles Labitte), et que SainteBeuve aurait volontiers fait passer «de la bibliothèque " à «l'écurie » (p. 9). Le petit ouvrage, d'une écriture soignée et élégante, se présente comme une biographie intellectuelle organisée en cinq chapitres aux titres suggestifs : "Un médiéviste précoce ", « Un bibliomane romantique ", « Un universitaire indiscipliné », " Un martyr de l'érudition », " Un fou d'écriture et de typographie ». La vie de F. Michel est marquée par des drames privés (l'emprisonnement de sa mère dans son enfance, une fausse accusation de viol à Londres, sa santé fragile, les déboires de son fils), par des déconvenues répétées (échec à l'entrée de la toute nouvelle École des Chartes, échec de ses diverses tentatives pour obtenir une situation officielle stable qui le satisfasse, bien qu'en 1839 il eût obtenu un poste de professeur à l'Université de Bordeaux - alors qu'il n'avait lors de sa nomination que le baccalauréat-, son enseignement se révéla catastrophique et aboutit à terme à son départ en 1869), et surtout par une absence de reconnaissance scientifique sûre (ses travaux ne firent jamais vraiment autorité). Le milieu où il évolue est cerné de manière précise, en particulier ses liens, fluctuants, avec Charles Nodier, qui lui servit de modèle bien que celui-ci, en dernier ressort, eût 
plutôt tendance à le mépriser. C'est du reste l'intérêt pour C. Nodier, auquel D. Barrière a consacré une étude en 1989, qui explique cette attention accordée à cet épigone peu sûr dont, toutefois, les pas ont croisé entre autres ceux d'Alexandre Dumas, de Nerval ou de Prosper Mérimée (avec lequel il a entretenu une abondante correspondance).

2 L'un des titres réels de gloire de F. Michel est d'avoir retrouvé en 1835 à Londres, où il avait réussi à obtenir une mission scientifique, le plus ancien manuscrit de la Chanson de Roland. C'est, au demeurant, lui qui lui donna pour la première fois ce titre. Il en publia une édition malheureusement confidentielle, de sorte qu'en 1850 François Génin se crut autorisé à en donner une autre édition à l'Imprimerie nationale, en ne mentionnant qu'une fois, et de manière peu visible, le nom du vrai découvreur.

3 L'érudition de F. Michel le mit sur la piste d'un vrai sujet - celui de sa thèse soutenue en 1846 à la Sorbonne - consacrée à l'ostracisme dont souffraient les «cagots »; mais le résultat obtenu ne fut pas à la hauteur et tenait davantage de l'«accumulation » de références que d'une réflexion historique accomplie.

4 La bibliographie de F. Michel est impressionnante, « innombrable », pléthorique. Mais, comme l'écrit D. Barrière, "aucune des études imprimées ne peut être qualifiée de livre », lesquelles s'apparentent plutôt à une accumulation brute de « dossiers » (p. 69). D. Barrière parle de «boulimie textuelle » (p. 80). La production incessante d'ouvrages s'explique aussi en partie, chez F. Michel, comme une stratégie pour offrir et donc recevoir des livres (p.58). Son œuvre ne repose sur "aucune pensée cohérente» (p. 60). D. Barrière résume le problème central avec une lucidité cinglante : «sagacité bibliographique hors du commun et incapacité littéraire, tel est l'humiliant paradoxe plus ou moins avoué de Francisque Michel » (p. 61).

5 Cette limite sérieuse au travail historique de F. Michel se retrouve aussi dans les autres genres où il s'est essayé. Ses tentatives romanesques n'eurent guère de succès (ses mélanges de fiction et de vie réelle furent plus heureux, selon D. Barrière - cependant la nouvelle à clefs, Les Derniers Moments, que ce dernier insère dans son étude, ne paraît pas inoubliable...). F. Michel se plut aussi, comme C. Nodier, dans les pastiches et les supercheries littéraires - un point qui retient particulièrement D. Barrière, lui-même " éditeur " d'un délicieux recueil de trois nouvelles de quasi-science fiction, Aux abords $d u$ fantastiques (Talence, l'Arbre Vengeur, 2013), aux tonalités différentes dont il cache, tel Pessoa, sa paternité unique derrière de faux noms d'auteurs. Ainsi F. Michel publie les Chroniques de Jacques Gondar clerc, fausses chroniques médiévales suivies d'une «fausse postface » du vrai C. Nodier. C'est aussi à F. Michel que D. Barrière attribue, avec quelques arguments, la fausse affaire du «bibliomane assassin » parue dans la Gazette des tribunaux en 1836, pour laquelle on avait pu souffler le nom de C. Nodier.

6 Le comportement de ce savant inabouti qu'était $\mathrm{F}$. Michel ne le rend pas plus sympathique, à en croire D. Barrière. Connu pour être mauvaise langue, passablement hypocrite, peu fiable, plaintif et coléreux, d'une prétention et d'une vanité sans proportion avec ses mérites réels, sensible à la gloriole de tous les titres honorifiques possibles qu'il avait pu recevoir - beaucoup sans grande utilité -, le personnage ne suscite guère l'empathie, malgré les difficultés et les drames auxquels il eut à faire face et la réelle et sincère passion du Moyen Âge qui l'animait.

7 Cependant, outre ses indéniables découvertes et la quantité de sources qu'il a mises à jour, F. Michel se voit reconnaître par D. Barrière trois contributions importantes : ses qualités de critique érudit, au moins dans une certaine mesure (p. 45), son rôle dans la 
diffusion des textes grâce à ses nombreux réseaux, et son goût pour la typographie et les beaux livres (p. 85).

8 La belle étude - non universitaire - de D. Barrière, à l'érudition sûre (sources, bibliographie, liste des travaux de F. Michel, et certains de ses textes sont donnés en annexe), ressuscite un milieu et une époque: les débuts encore parfois un peu brouillons de l'érudition sur fond de passion romantique pour le Moyen Âge. Le parcours erratique d'un Francisque Michel, dans sa signifiante singularité, offre un excellent poste d'observation pour cette historiographie. 